\title{
Squamous cell carcinoma antigen 1 and 2 mRNA and a new variant expressed in hepatocellular carcinoma
}

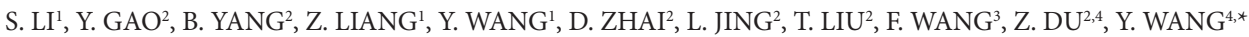 \\ ${ }^{1}$ Third Central Clinical College of Tianjin Medical University, Tianjin 300170, China; ${ }^{2}$ Key Laboratory of Artificial Cell, Institute for Hepatobiliary \\ Disease, Third Central Hospital of Tianjin, Tianjin, China; ${ }^{3}$ Department of Gastroenterology and Hepatology, Third Central Hospital of Tianjin, \\ Tianjin, China; ${ }^{4}$ Department of Hepatobiliary Surgery, Third Central Hospital of Tianjin, Tianjin, China
}

*Correspondence: wangyj@medmail.com.cn

Received December 1, 2013 / Accepted March 13, 2014

\begin{abstract}
New tools for diagnostic of HCC remain to further investigate. We have evaluated the expression of SCCA1, 2 mRNA and their prognostic value in hepatocellular carcinoma (HCC).

Reverse transcription polymerase chain reaction (RT-PCR) and direct sequencing were performed to evaluate the mRNA expression of SCCA1 and SCCA2 in 93 HCCs, and 93 paired adjacent non-cancerous tissues (PNT), 16 cirrhosis livers and 9 normal livers. The correlation of SCCA variants expression with the clinical parameters and the factors affecting survival were analyzed statistically.

Total SCCA was detected in 33.3\% of HCCs (31/93), in 9.68\% of PNT (9/93) and 22.2\% of normal livers (2/9). No expression was found in cirrhosis livers (0/16). The frequencies of total SCCA expression were significantly higher in HCCs than that in PNT and liver cirrhosis ( $\mathrm{p}=0.000,0.006$ ). From mRNA sequencing of HCCs, a new SCCA1 variant (presenting a T357A mutation) was identified in 16 specimens, while wild type SCCA1 was identified in 11 specimens and SCCA2 in 27 specimens. Clinicopathological analysis showed that the frequency of SCCA1 was significantly higher in poorly differentiated HCC, compared with moderately and well differentiated tumors $(\mathrm{p}=0.021)$. T357A variant has a significantly higher frequency in nonencapsulated tumors than wild type SCCA1 $(\mathrm{p}=0.034)$.

The SCCA1, 2 mRNA is effective for detecting HCC and could be potentially applied in HCC diagnosis.
\end{abstract}

Key words: hepatocellular carcinoma, liver diseases, prognosis, squamous cell carcinoma antigen

Liver cancer is the fifth most frequently diagnosed cancer but the second most frequent cause of cancer death in men worldwide (half of these cases and deaths are estimated to occur in China), and approximately, $70-85 \%$ of the total liver cancer are classified as hepatocellular carcinoma (HCC) [1]. Early detection enables us to provide the patients with more therapeutic options, which can improve survival rate of patients and reduce medical costs [2]. Despite the fact that serum AFP is still the golden standard amongst diagnostic markers for HCC, its diagnostic value is more and more questioned, because of its poor sensitivity and specificity $[3,4]$. Therefore, investigators are seeking for better HCC biomarkers.

Squamous cell carcinoma antigen (SCCA), originally isolated from SCC tissue of the uterine cervix, is a member of the family of serine protease inhibitors [5]. The neutral and acidic isoforms of SCCA are encoded by 2 separate, but highly homologous genes, SCCA1 and SCCA2, at chromosome 18q21.3 [6]. Although SCCA1 and SCCA2 are with $91 \%$ identity at the amino acid concentration, they have distinct properties and substrate specificities. SCCA1 also known as SERPINB3, a papain-like cysteine proteinase inhibitor, inhibits cathepsins K, L and S [7]. SCCA2 also known as SERPINB4, a chymotrypsin-like serine proteinase inhibitor, inhibits proteolytic activity of endogenous cathepsin $\mathrm{G}$ and mast cell chymase [8]. The biological role of this serpin in carcinogenesis has not been yet completely defined. It has been reported that both SCCA 1 and SCCA 2 protect neoplastic cells from apoptotic death $[9,10]$ and that SCCA1 promotes tumor growth, epithelial to mesenchymal transition (EMT) and cell proliferation $[11,12]$.

The over-expression of SCCA was initially described in many different cancers of epithelial origin such as head and 
neck, vulvar, lung and oesophageal tumors [13-16]. Recently Pontisso et al. [17] detected SCCA expression in HCC by immunohistochemistry for the first time but the expression pattern of SCCA1 and SCCA2 in cancer pathogenesis is not fully defined. Biasiolo et al. [18] quantified IgM-linked SCCA1, 2 isoforms in serum of patients with chronic liver diseases, however, their result could not represent the expression of SCCA isoforms in HCC since no correlation was found between serum and tissue levels of SCCA antigen [19]. Furthermore, to date no information is available on the clinical and prognostic significance of SCCA variants. In the present study, our aim was to study the expression of the SCCA1 and SCCA2 genes in malignant, PNT, cirrhosis and normal liver tissue, and to clarify the clinical and prognostic significance of SCCA variants in HCC.

\section{Patients and methods}

Patients and tissue samples. A total of 211 tissue samples were collected from Department of Hepatobiliary Surgery and Hepatology of Tianjin Third Central Hospital in China between January 2004 and December 2009. 93 paired tumor and PNT were obtained by hepatectomy from HCC patients. Liver cirrhosis $(\mathrm{n}=16)$ were obtained by ultrasound-guided core-needle biopsy. All specimens were obtained from patients before treatment. The final diagnosis was confirmed by histopathological analysis. Tumors were classified according to World Health Organization classification and the TNM classification system of International Union against Cancer (Edition 6). Normal liver samples $(n=9)$ were from hepatic hemangioma patients (normal controls) without chronic hepatitis or cirrhosis. All PNT samples were collected $2 \mathrm{~cm}$ away from the tumor border, and 86 of them were cirrhotic liver tissues diagnosed by pathological examination. All tissues were snap frozen at time of operation, without jeopardizing the diagnostic or therapeutic procedure to the patients. All participants provided written informed consent according to the guidelines of the Ethics Committee of Tianjin Third Central Hospital. This study was performed according to the principles of the Declaration of Helsinki.

Patients follow up. The follow-up period was defined as the time from the date of surgery to the date of patient death or the last follow-up point. Follow-up was completed in 15 July 2012. All HCC patients were followed up. Diagnosis of recurrence was confirmed by ultrasound, enhanced CT scan, MRI and AFP levels.

RNA extraction and reverse-transcription. Total RNA was purified from frozen tissue samples $(50 \mathrm{mg})$ with the Trizol reagent (Invitrogen, San Diego, CA, USA), following the manufacturer's instructions. The concentration and quality of total RNA were measured by spectrophotometer at $260 \mathrm{~nm}$ and $280 \mathrm{~nm}$ (A260/280 ratio) and determined by agarose gel electrophoresis.

For cDNA synthesis, $3 \mu \mathrm{g}$ total RNA of a sample were reverse-transcribed using ImProm-II ${ }^{\mathrm{TM}}$ Reverse Transcriptase
System (Promega, Madison, WI, USA) according to the manufacturer's instructions cDNA was stored at $-20^{\circ} \mathrm{C}$ for further use.

Evaluation of SCCA1 and SCCA2 by RT-PCR and sequencing. To accurately estimate SCCA1 and SCCA2 gene expression, two strategies were performed including RT-PCR with sequence specific primers and sequencing the production amplified with universal primers.

RT-PCR with sequence specific primers. In this strategy, the expression of SCCA1 and SCCA2 mRNA was measured with the real-time reverse transcriptase-polymerase chain reaction (RT-PCR) method using SYBR green. RT-PCR was performed using 384-microwell plates in $\mathrm{ViiA}^{\mathrm{TM}} 7$ Real-Time PCR System (Applied Biosystems, Carlsbad, CA, USA). Special primers were designed as follows: sense primer for SCCA1, 5'-ATTCCTGAAGGTAATATTGGCAGCA-3', SCCA2, 5'TTTCCTGATGGGACTATTGGCAATG-3'; reverse primer for SCCA1, 5'-GTTGAAGYAGGTGATGATCCGAATC-3', SCCA2, 5'-GTTGAAGGAGATGATAATTCGACTA-3'; the amplicon size was $590 \mathrm{bp}$ for both of SCCA1 and 2. Fifteen microliters of reaction system was used for RT-PCR (TaKaRa Biotechnology, Dalian,China), including $1.5 \mu \mathrm{L}$ cDNA, $0.35 \mu \mathrm{L}$ sense primer and $0.35 \mu \mathrm{L}$ reverse primer $(10 \mathrm{mM}), 0.5 \mu \mathrm{L}$ Sybrgreen $(25 \times), 1.2 \mu \mathrm{L}$ deoxyribonucleotide triphosphate

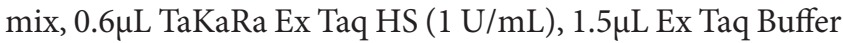
$\left(\mathrm{Mg}^{2+} \mathrm{Plus}\right)$, with $9 \mu \mathrm{L} \mathrm{ddH}_{2} \mathrm{O}$ added up to $15 \mu \mathrm{L}$. The glyceraldehyde-3-phosphate dehydrogenase (G3PDH) was analysed in all amplification sets to assess the integrity of total RNA extracts with the primers: sense, 5'-GGGCATCCTGGGCTACACTGA3', reverse, 5'-CAAATTCGTTGTCATACCAGGAAATG-3', the amplicons size was $143 \mathrm{bp}$. Amplification conditions were: 5 min at $94^{\circ} \mathrm{C}$, and a two-step cycle of $94^{\circ} \mathrm{C}$ for 30 s and $62^{\circ} \mathrm{C}$ for 60 s for a total of 45 cycles. After PCR, melting curve analysis was performed. Specificity of the amplified PCR products was determined by melting curve analysis. Data of positive samples were normalized using the G3PDH housekeeping gene, and the relative amount of SCCA 1 and SCCA 2 mRNA were calculated with the formula: target gene $=2^{-\triangle \mathrm{CT}}[\Delta \mathrm{CT}=\mathrm{CT}(\mathrm{SCCA} 1)$ - CT(G3PDH)]. All of quantitative analyses were carried out in duplicate to determine consistency of results.

Sequencing and sequence analysis. To validate the expression of SCCA1 and SCCA2 and distinguish transcriptional variants, we used convention PCR by consensus primers designed for amplify both SCCA1 and SCCA2 and then sequenced the amplified production in this strategy. Briefly, $1 \mathrm{U} / \mathrm{mL}$ of Taq polymerase (TaKaRa Biotechnology, Dalian, China) and the following primers were used: sense, 5'-GATGGTCTSCAGAAGCTTGAAGAG-3', reverse, 5'CTGCCATAGAAGAGGATGCTGTTG-3'. After 40 cycles at $94^{\circ} \mathrm{C} 5 \mathrm{~min}$, and a two-step cycle of $94^{\circ} \mathrm{C}$ for 30 s and $62^{\circ} \mathrm{C}$ for $60 \mathrm{~s}$, we analysed amplified products by $2.5 \%$ agarose gel electrophoresis. Samples positive for the expected $404 \mathrm{bp}$ band obtained were sequenced by Invitrogen Corporation (Shanghai, China), sequence chromatogram files were opened and viewed by BioEdit (Tom Hall, Carlsbad, CA). 


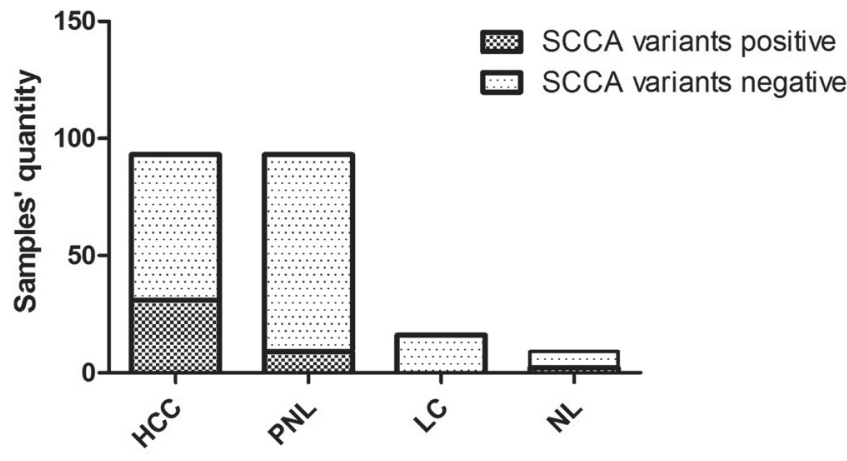

Figure 1. Distribution of SCCA variants in all 211 samples. SCCA variants were positive in 31 out of 93 HCC samples, 9 out of 93 PNT samples, none of $16 \mathrm{LC}$ and 2 out of 9 NL samples. SCCA variants were significantly higher in HCC samples than in PNT $(p=0.000)$ or LC samples $(p=0.006)$. LC = liver cirrhosis $\mathrm{NL}=$ normal liver $\mathrm{PNL}=$ paired adjacent non-cancerous tissues SCCA= Squamous cell carcinoma antigen

Statistical analysis. Pearson's chi-square $\left(\chi^{2}\right)$ test or Fisher's exact test were used for the analysis of the results. Quantitative data were presented as median (range, 25th and 75th percentiles). The Mann-Whitney U-test was used to compare the differences among the groups. Cancer specific survival time was calculated according to the Kaplan-Meier method. The log-rank test was used to compare the groups. Univariate and Multivariate Cox proportional hazards models were fitted to the data to determine the importance of covariates. Factors that were prognostically relevant in univariate analysis were included in multivariate Cox analysis. Estimates for hazard ratios (HR) were reported with 95\% confidence intervals (CI).
Statistical significance was assumed for P-values less than 0.05. All these analysis were performed with SPSS 17.0.

\section{Results}

SCCA variants expression in HCC tissues. In RT-PCR with sequence specific primers strategy, SCCA1 was found in $\operatorname{HCC}(\mathrm{n}=27)$, PNT $(\mathrm{n}=7)$ and normal liver $(\mathrm{n}=1)\left[4.77 \times 10^{-5}\right.$ $\left(5.65 \times 10^{-6} 1.01 \times 10^{-4}\right), 1.72 \times 10^{-5}\left(4.65 \times 10^{-6} 6.31 \times 10^{-5}\right), 1.25 \times 10^{-5}$ respectively]. Similar values of expression were obtained for SCCA2, 27 of the $93 \mathrm{HCC}, 8$ of the 93 PNT and 2 of the 9 normal liver were positive $\left[2.12 \times 10^{-5}\left(5.52 \times 10^{-6} 5.38 \times 10^{-5}\right), 1.34 \times 10^{-5}\right.$ $\left(6.62 \times 10^{-6} 2.89 \times 10^{-5}\right), 1.22 \times 10^{-5}, 1.08 \times 10^{-5}$ respectively]. It was worth noting that SCCA 1,2 simultaneously expressed in 23 HCC, 6 PNT and 1 normal liver specimens. All 16 liver cirrhosis specimens were negative for SCCA1 and 2. In the other strategy, the results were consistent with those obtained above. Total SCCA was positive in $33.3 \%$ of patients with HCC (31/93), in $9.68 \%$ of PNT (9/93) and $22.2 \%$ of normal liver (2/9). None expression was found in cirrhosis livers $(0 / 16)$ in the same experimental conditions. The frequencies of total SCCA expression were significantly higher in HCC than that in PNT and liver cirrhosis ( $\mathrm{P}=0.000,0.006)$ (Figure 1$)$. Limited by the small number of normal liver patients, we could not assess the differences between HCC and normal liver group.

In order to distinguish transcriptional variants, we sequenced positive samples for SCCA, and compared the sequences with reported sequences at NCBI GenBank. The sequencing results showed that the SCCA sequence of HCC had complete homology with SCCA1 in 11 specimens and with SCCA2 in 27 specimens. A new SCCA1 variant, present-
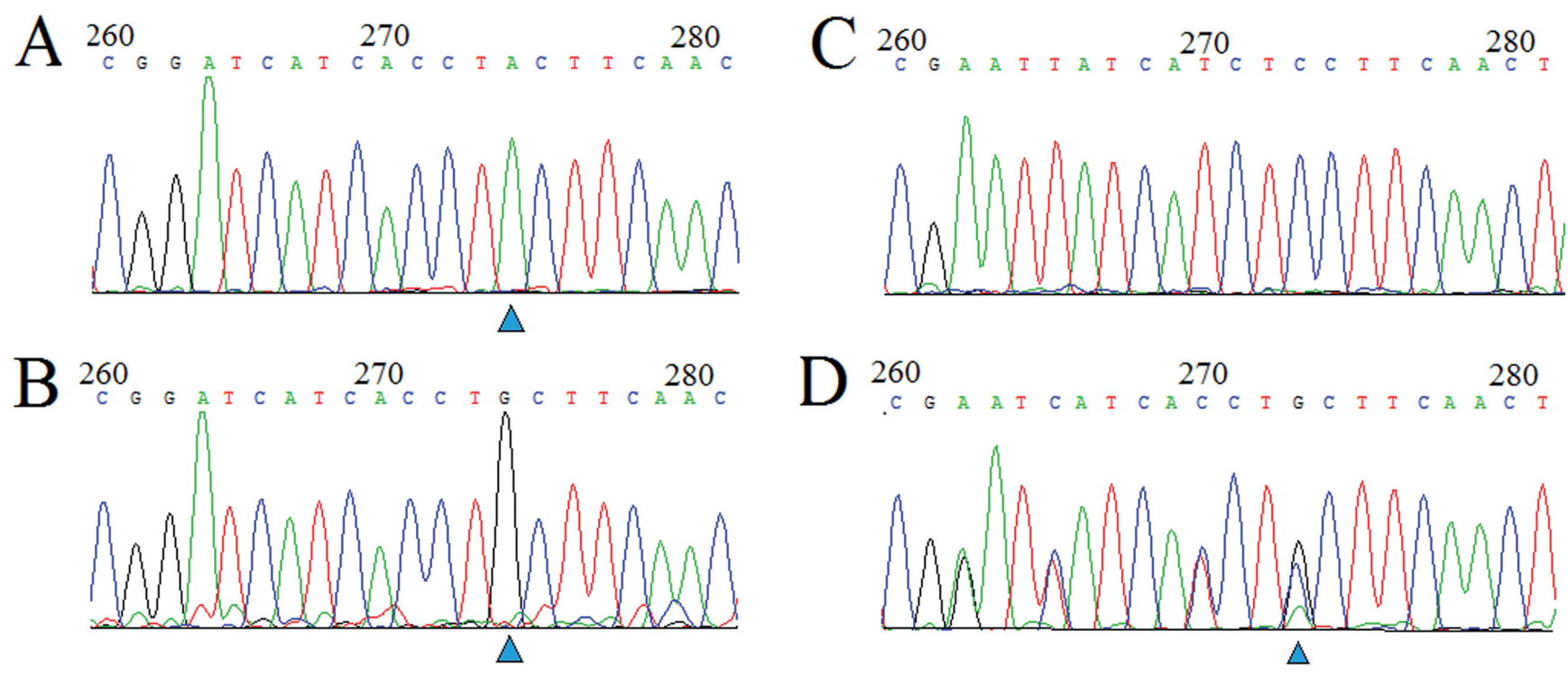

Figure 2. Chromatogram excerpt of sequenced cDNA amplicons derived from HCC patients. Sequence A was identified as SCCA1 wild type; sequence B was identified as SCCA1 mutation; sequence C was identified as SCCA2; sequence D was identified as a mixed expression characterized by the appearance of double or three peaks at the distinctive nucleotide positions. 

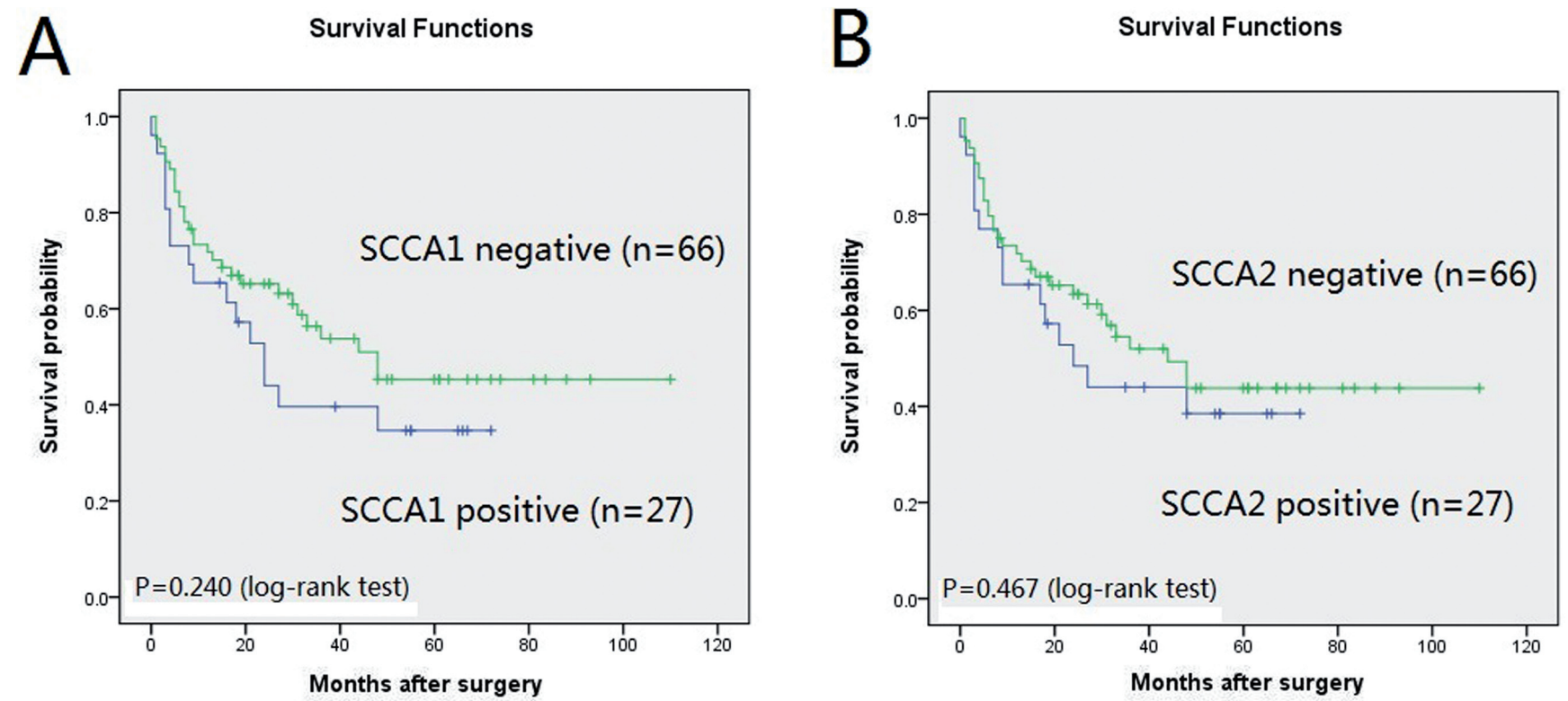

Figure 3. Correlation between SCCA1, 2 expression and the prognosis of hepatocellular carcinoma (HCC) patients. Significant differences was found in neither SCCA1-positive nor SCCA2-positive group $(\mathrm{P}=\mathbf{0 . 2 4 0}, \mathrm{P}=\mathbf{0 . 4 6 7})$. However, a trend for poorer survival in SCCA variants positive group could be found (median survival 24 months vs 48 months, 24 months vs 44 months, overall 1 - and 2 -year survival rates $65.38 \%$ and $38.46 \%$ vs $70.31 \%$ and $53.13 \%, 65.38 \%$ and $42.31 \%$ vs $70.31 \%$ and $51.56 \%)$.

ing a T357A (c. 1069A $>\mathrm{G})$ mutation in the reactive centre loop of the protein, was identified in 16 specimens (Figure 2). Furthermore, we analysed the allele frequencies for Thr357 among the 27 SCCA1-positive HCC specimens. The genotypic frequencies were AA 40.7\% (11/27), AG 29.6\% (8/27) and GG $29.6 \%(8 / 27)$; the $G$ allelic frequency was 0.44 . In addition, the new variant was observed in all SCCA1-positive PNT $(n=7)$ and normal liver $(n=1)$ specimens.

Recently it was reported that expression of SCCA-PD, a variant presenting G351A mutation, detected in one third of HCCs [17]. However, only 2 of 31 SCCA positive HCCs were found SCCA-PD-expressing in the present study, and the 2 specimens express the T357A mutation at the same time.

To evaluate whether SCCA variants could be used as a biomarker for HCC, we examined their association with AFP levels. Of 93 patients, 40 (43.0\%) were sero-positive for AFP, and 31 (33.3\%) were positive for SCCA variants. There was no statistical significance between diagnostic efficiency of SCCA variants and that of AFP ( $p>0.05)$, which indicated that the expression of SCCA variant was not associated with AFP in many HCCs. The positive rate for SCCA variants was $35.8 \%$ (19/53) in AFP-negative HCCs and the positive rate for AFP was 45.2\% (28/62) in SCCA-negative HCCs. However, the positive rate in collaborative use of AFP and SCCA variants was increased up to $63.4 \%$ (59/93). As a consequence, the level of at least one of the two markers was elevated in the majority of HCC patients.

SCCA variants and clinicopathological features. To better understand the importance of SCCA variants expression in
HCC, the relationship between SCCA variants and 14 clinicopathologic characteristics was analyzed (Table S1). The positive rate of SCCA1 was associated with tumor grade, as $42.9 \%$ of poorly differentiated samples tested positive for SCCA 1 expression, whereas only $31.7 \%$ and $8.3 \%$ of moderately and well differentiated tumors showed SCCA1 expression $(\mathrm{p}=0.021)$. No significant difference was detected for the other clinical and biochemical parameters, including age, sex, tumor size, TNM stage, and so on (All p > 0.05).

In addition, we assessed the clinical and tumor behaviour parameters in relation to SCCA1 polymorphism. In SCCA1positive patients, two groups were identified on the basis of SCCA1 polymorphism: group A included 11 patients with SCCA1 wild type, while the remaining 16 patients (group B) with SCCA1 new variant. The percentage of tumor with complete capsule was lower in group B than group A and the difference was significant ( $\mathrm{p}=0.034$ ) (Table S2). No significant association was found in the other clinicopathological parameters.

Correlation between SCCA expression and the prognosis of HCC patients. By the last follow-up, in July 2012, the median follow up time was 46 months (range 2-93 months), $56.99 \%$ (53/93) of the patients had suffered from a recurrence and $49.46 \%$ (46/93) died.

Patients with HCC were divided into two groups according to their SCCA mRNA expression profiles. For SCCA1, median survival was 24 months for the positive group and 48 months for the negative group. The overall 1 - and 2-year survival rates were $65.38 \%$ and $38.46 \%$, respectively for the positive group, and $70.31 \%$ and $53.13 \%$, respectively for the negative group. Simi- 
larly for SCCA2, median survival was 24 months for the positive group and 44 months for the negative group. The overall 1- and 2 -year survival rates were $65.38 \%$ and $42.31 \%$, respectively for the positive group, and $70.31 \%$ and $51.56 \%$, respectively for the negative group. Although there were no significant differences in the overall survival between SCCA-positive and SCCA-negative groups (log-rank test, $p=0.240$, Figure $3 \mathrm{~A} ; \mathrm{p}=0.467$, Figure $3 \mathrm{~B}$, respectively), a trend for poorer survival in SCCA variants positive group could be found.

Furthermore, univariable analysis revealed that Child-Pugh score, AFP level, tumor number, tumor size, vascular invasion, capsule formation, TNM stage, tumor grade were adverse prognostic factors for survival after resection $(\mathrm{p}=0.045$, $0.013,0.004,0.000,0.000,0.000,0.016,0.040$ ). Multivariable analysis indicated that AFP level and capsule formation were independent prognostic factors with the relative risk of 4.416 (95\%CI 1.784 10.935), 3.234 (95\%CI 1.291 8.102) respectively (Table S3).

\section{Discussion}

In the present study a specific detection system for SCCA variants in patients with different extent of chronic liver diseases was established. Previous researches revealed that IgM-linked immunocomplexes instead of the free isoforms could be detected in serum of chronic liver disease patients $[20,21]$. However, no correlation was found between serum and tissue levels of SCCA antigen [19], so serum SCCA1, 2 concentrations could not represent the level of SCCA1, 2 expression in HCC tissue and the expression of SCCA1, 2 in HCC tissue remains unknown. The aim of this investigation was to study the pattern of expression of the SCCA1 and SCCA2 in different extent of liver diseases, and to define the clinical and prognostic significance in HCC.

The results obtained in the present study indicated that the positive expression rates of SCCA variants were significantly higher in HCC compared with PNT and liver cirrhosis specimens. One of the main features of a good marker for HCC is its ability to distinguish tumor from cirrhotic liver. In our study, SCCA variants were found in HCC but not in liver cirrhosis. Moreover, the positive rate in collaborative use of AFP and SCCA variants increased up to $63.4 \%$. Therefore, SCCA variants could be used as a supplementary to AFP in the diagnosis of HCC. This suggests that the simultaneous detection of AFP and SCCA variants should be effective particularly for the diagnosis of HCC.

Turato [22] found SCCA1 was over-expressed especially in the more immature compartments of hepatoblastoma which may have a role in regulating the growth of immature hepatic tissue. The elevated expression of SCCA 1 has also been shown to be associated with poorly differentiated breast carcinoma [23]. In our study, the frequency of SCCA1 in poorly differentiated HCCs was significantly higher than that in well and moderately differentiated HCCs. Given the function of inducing EMT and increasing invasiveness and proliferative potential, the high expression of SCCA1 in poorly differentiated carcinoma may explain why the poorly differentiated tumor usually has a more aggressive clinical behaviour.

SCCA1, also known as SerpinB3, is a member of the family of serine protease inhibitors. The mechanism of protease inhibition depends on interaction of the protease with the reactive center loop (RCL) of the serpin. The RCL, which contains the proteinase recognition site, has been demonstrated to be essential [24]. Alteration to the specific amino acid in the reactive center might change the functional activity of the serpin. Previous mutational studies related to SCCA1 have demonstrated that mutation of G353R made SCCA1 acquire trypsin inhibitory activity [24]. Moreover mutation of G351A, termed SCCA-PD, has a higher proteinase inhibitory activity than wild type SCCA1, while the mutation of $\mathrm{F} 352 \mathrm{G}$ causes a decrease inhibitory activity [25]. As for SCCA-PD, it was detected in $2.2 \%$ of HCC patients in our study, whereas an Italian study shown that $35.7 \%$ of HCCs was SCCA-PD positive [17]. The discrepancies in findings maybe caused by variations ethnic background. Based on mRNA sequencing, a T357A mutation was detected in $59.3 \%$ of SCCA1 positive HCC patients for the first time. Analysis in a functional point of view, the RCL of SCCA1 should be exposed to a solvent to bind proteinases. The amino acid changed by Ala in a part of the RCL shows strong hydrophobic features, suggesting that the RCL should be more easily to bind proteinases by hydrophobic interactions. This is one explanation for the increased inhibitory activity of SCCA-PD. In the present study, we found amino acid of the new SCCA1 variant was also replaced by Ala. Same as the change of SCCA-PD, we speculate the new SCCA1 variant could have an increased inhibitory activity. We have attempted to evaluate whether the different SCCA1 polymorphism influenced differently in patients with HCC. Our analysis has shown that the frequency of T357A variant is significantly higher in nonencapsulated tumors, compared to encapsulated tumor, suggesting a greater invasive potential of this variant, compared to wild type SCCA1.

To our knowledge, this is the first time to analyze the correlation between SCCA1, 2 expression and the prognosis of HCC patients. Our findings document that positive SCCA variants patients have a trend for poorer survival through the analysis of the median survival and 1-, 2- year survival.

In conclusion, SCCA1, 2 mRNA of patients with chronic liver diseases were investigated. This study reveals that the SCCA variants have a high frequency in patients with HCC and could be potentially applied in HCC diagnosis. What's more, a new SCCA1 variant firstly identified. This finding allows to generate important hypotheses on the role of this genetic expression in HCC. We will carry out a multicenter and further large-scale study to confirm these results.

Acknowledgements: This study was supported in grants from Tianjin Research Project on Basic Science and Frontier Technology (No. 12CZOSY02700) and the Key Research Project of Tianjin Healthy Bureau (11KG112). 


\section{References}

[1] JEMAL A, BRAY F, CENTER MM, FERLAY J, WARD E, et al. Global cancer statistics. CA: a cancer journal for clinicians 2011; 61: 69-90 http://dx.doi.org/10.3322/caac.20107

[2] AVILA MA, BERASAIN C, SANGRO B, PRIETO J. New therapies for hepatocellular carcinoma. Oncogene 2006; 25: 3866-3884 http://dx.doi.org/10.1038/sj.onc.1209550

[3] WILLYARD C. Researchers look for ,sweet' method to diagnose cancer. Nat Med 2007; 13: 1267 http://dx.doi. org/10.1038/nm1107-1267

[4] BENOWITZ S. Liver cancer biomarkers struggling to succeed. J Natl Cancer Inst 2007; 99: 590-591 http://dx.doi. org/10.1093/jnci/djk174

[5] KATO H. Expression and function of squamous cell carcinoma antigen. Anticancer Res 1996; 16: 2149-2153

[6] SCHNEIDER SS, SCHICK C, FISH KE, MILLER E, PENA JC, et al. A serine proteinase inhibitor locus at 18q21.3 contains a tandem duplication of the human squamous cell carcinoma antigen gene. Proc Natl Acad Sci U S A 1995; 92: 3147-3151 http://dx.doi.org/10.1073/pnas.92.8.3147

[7] SCHICK C, PEMBERTON PA, SHI GP, KAMACHI Y, CATALTEPE S, et al. Cross-class inhibition of the cysteine proteinases cathepsins $\mathrm{K}, \mathrm{L}$, and $\mathrm{S}$ by the serpin squamous cell carcinoma antigen 1: a kinetic analysis. Biochemistry 1998; 37: 5258-5266 http://dx.doi.org/10.1021/bi972521d

[8] SCHICK C, KAMACHI Y, BARTUSKI AJ, CATALTEPE S, SCHECHTER NM, et al. Squamous cell carcinoma antigen 2 is a novel serpin that inhibits the chymotrypsin-like proteinases cathepsin G and mast cell chymase. J Biol Chem 1997; 272: 1849-1855 http://dx.doi.org/10.1074/jbc.272.3.1849

[9] VIDALINO L, DORIA A, QUARTA S, ZEN M, GATTA A, et al. SERPINB3, apoptosis and autoimmunity. Autoimmun Rev 2009; 9: 108-112 http://dx.doi.org/10.1016/ j.autrev.2009.03.011

[10] MURAKAMI A, SUMINAMI Y, HIRAKAWA H, NAWATA S, NUMA F, et al. Squamous cell carcinoma antigen suppresses radiation-induced cell death. Br J Cancer 2001; 84: 851-858 http://dx.doi.org/10.1054/bjoc.2000.1683

[11] QUARTA S, VIDALINO L, TURATO C, RUVOLETTO M, CALABRESE F, et al. SERPINB3 induces epithelial-mesenchymal transition. J Pathol 2010; 221: 343-356 http://dx.doi. org/10.1002/path.2708

[12] VILLANO G, QUARTA S, RUVOLETTO MG, TURATO C, VIDALINO L, et al. Role of squamous cell carcinoma antigen1 on liver cells after partial hepatectomy in transgenic mice. Int J Mol Med 2010; 25: 137-143

[13] KIMURA Y, FUJIEDA S, TAKABAYASHI T, TANAKA T, SUGIMOTO C, et al. Conventional tumor markers are prognostic indicators in patients with head and neck squamous cell carcinoma. Cancer Lett 2000; 155: 163-168 http://dx.doi. org/10.1016/S0304-3835(00)00423-7

[14] CHECHLINSKA M, KOWALEWSKA M, BRZOSKA-WOJTOWICZ E, RADZISZEWSKI J, PTASZYNSKI K, et al. Squamous cell carcinoma antigen 1 and 2 expression in cultured normal peripheral blood mononuclear cells and in vulvar squamous cell carcinoma. Tumor Biol 2010; 31: 559-567 http://dx.doi.org/10.1007/s13277-010-0069-x

[15] KASHIWABARA K, NAKAMURA H, YAGYU H, KISHI K, MATSUOKA T, et al. Changes in squamous cell carcinoma-related antigen levels before and after hemodialysis in relation to the model of dialyzer employed. Intern Med 2000; 39: 291-295 http://dx.doi.org/10.2169/ internalmedicine.39.291

[16] SHIMADA H, NABEYA Y, OKAZUMI S, MATSUBARA H, SHIRATORI T, et al. Prediction of survival with squamous cell carcinoma antigen in patients with resectable esophageal squamous cell carcinoma. Surgery 2003; 133: 486-494 http:// dx.doi.org/10.1067/msy.2003.139

[17] PONTISSO P, CALABRESE F, BENVEGNU L, LISE M, BELLUCO C, et al. Overexpression of squamous cell carcinoma antigen variants in hepatocellular carcinoma. Br J Cancer 2004; 90: 833-837 http://dx.doi.org/10.1038/sj.bjc.6601543

[18] BIASIOLO A, TONO N, RUVOLETTO M, QUARTA S, TURATO C, et al. IgM-Linked SerpinB3 and SerpinB4 in Sera of Patients with Chronic Liver Disease. PLoS One 2012; 7: e40658 http://dx.doi.org/10.1371/journal.pone.0040658

[19] GIANNELLI G, MARINOSCI F, SGARRA C, LUPO L, DENTICO P, et al. Clinical role of tissue and serum levels of SCCA antigen in hepatocellular carcinoma. Int J Cancer 2005; 116: 579-583 http://dx.doi.org/10.1002/ijc.20847

[20] BENEDUCE L, CASTALDI F, MARINO M, QUARTA S, RUVOLETTO M, et al. Squamous cell carcinoma antigenimmunoglobulin $\mathrm{M}$ complexes as novel biomarkers for hepatocellular carcinoma. Cancer 2005; 103: 2558-2565 http://dx.doi.org/10.1002/cncr.21106

[21] SOYEMI OMD, OTEGBAYO JAD, OLA SOD, AKERE AD, SOYEMI TD. Comparative diagnostic efficacy of serum squamous cell carcinoma antigen in hepatocellular carcinoma. BMC Res Notes 2012; 5: 403 http://dx.doi.org/10.1186/17560500-5-403

[22] TURATO C, BUENDIA MA, FABRE M, REDON MJ, BRANCHEREAU S, et al. Over-expression of SERPINB3 in hepatoblastoma: a possible insight into the genesis of this tumor? Eur J Cancer 2012; 48: 1219-1226 http://dx.doi. org/10.1016/j.ejca.2011.06.004

[23] CATANZARO JM, GUERRIERO JL, LIU J, ULLMAN E, SHESHADRI N, et al. Elevated expression of squamous cell carcinoma antigen (SCCA) is associated with human breast carcinoma. PLoS One 2011; 6: e19096 http://dx.doi. org/10.1371/journal.pone.0019096

[24] SCHICK C, BROMME D, BARTUSKI AJ, UEMURA Y, SCHECHTER NM, et al. The reactive site loop of the serpin SCCA1 is essential for cysteine proteinase inhibition. Proc Natl Acad Sci U S A 1998; 95: 13465-13470 http://dx.doi. org/10.1073/pnas.95.23.13465

[25] ZHENG B, MATOBA Y, KUMAGAI T, KATAGIRI C, HIBINO T, et al. Crystal structure of SCCA1 and insight about the interaction with JNK1. Biochem Biophys Res Commun 2009; 380: 143-147 http://dx.doi.org/10.1016/j.bbrc.2009.01.057 


\title{
Supplementary Information
}

\section{Squamous cell carcinoma antigen 1 and 2 mRNA and a new variant expressed in hepatocellular carcinoma}

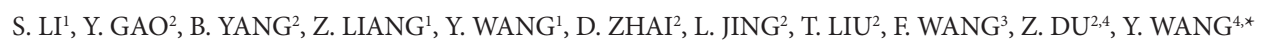

${ }^{1}$ Third Central Clinical College of Tianjin Medical University, Tianjin 300170, China; ${ }^{2}$ Key Laboratory of Artificial Cell, Institute for Hepatobiliary Disease, Third Central Hospital of Tianjin, Tianjin, China; ${ }^{3}$ Department of Gastroenterology and Hepatology, Third Central Hospital of Tianjin, Tianjin, China; ${ }^{4}$ Department of Hepatobiliary Surgery, Third Central Hospital of Tianjin, Tianjin, China

*Correspondence: wangyj@medmail.com.cn

Table S1 Correlation between SCCA variants expression and clinicopathological factors of HCC

\begin{tabular}{|c|c|c|c|c|c|c|c|c|c|c|c|c|c|c|}
\hline \multirow[t]{2}{*}{ Variable } & & \multirow{2}{*}{$\begin{array}{c}\text { Total } \\
\mathrm{n}\end{array}$} & \multicolumn{2}{|c|}{ SCCA } & \multirow[t]{2}{*}{$\chi^{2}$} & \multirow[t]{2}{*}{$\mathrm{P}$} & \multicolumn{2}{|c|}{ SCCA1 } & \multirow[t]{2}{*}{$\chi^{2}$} & \multirow[t]{2}{*}{$\mathrm{P}$} & \multicolumn{2}{|c|}{ SCCA2 } & \multirow[t]{2}{*}{$\chi^{2}$} & \multirow[t]{2}{*}{$\mathrm{P}$} \\
\hline & & & Positive & Negative & & & Positive & Negative & & & Positive & Negative & & \\
\hline \multirow[t]{2}{*}{ Sex } & Male & 79 & 27 & 52 & 0.168 & 0.682 & 24 & 55 & 0.462 & 0.496 & 23 & 56 & 0.002 & 0.967 \\
\hline & Female & 14 & 4 & 10 & & & 3 & 11 & & & 4 & 10 & & \\
\hline \multirow[t]{2}{*}{ Age(years) } & $\leq 55$ & 49 & 16 & 33 & 0.022 & 0.833 & 14 & 35 & 0.011 & 0.918 & 13 & 36 & 0.315 & 0.575 \\
\hline & $>55$ & 44 & 15 & 29 & & & 13 & 31 & & & 14 & 30 & & \\
\hline \multirow[t]{2}{*}{$\mathrm{HBV}$} & + & 75 & 24 & 51 & 0.310 & 0.578 & 21 & 54 & 0.200 & 0.654 & 22 & 53 & 0.017 & 0.896 \\
\hline & - & 18 & 7 & 11 & & & 6 & 12 & & & 5 & 13 & & \\
\hline \multirow[t]{2}{*}{$\mathrm{HCV}$} & + & 5 & 1 & 4 & 0.423 & 0.516 & 1 & 4 & 0.209 & 0.647 & 1 & 4 & 0.209 & 0.647 \\
\hline & - & 88 & 30 & 58 & & & 26 & 62 & & & 26 & 62 & & \\
\hline \multirow[t]{2}{*}{ Liver cirrhosis } & Yes & 86 & 28 & 58 & & 0.682 & 24 & 62 & & 0.410 & 26 & 60 & & 0.669 \\
\hline & No & 7 & 3 & 4 & & & 3 & 4 & & & 1 & 6 & & \\
\hline \multirow[t]{2}{*}{ Child-Pugh score } & $\mathrm{A}$ & 80 & 27 & 53 & 0.045 & 0.833 & 23 & 57 & 0.022 & 0.882 & 24 & 56 & 0.260 & 0.610 \\
\hline & B & 13 & 4 & 9 & & & 4 & 9 & & & 3 & 10 & & \\
\hline \multirow[t]{2}{*}{$\mathrm{AFP}(\mathrm{ng} / \mathrm{mL})$} & $\leq 400$ & 53 & 19 & 34 & 0.351 & 0.554 & 17 & 36 & 0.554 & 0.457 & 17 & 36 & 0.554 & 0.457 \\
\hline & $>400$ & 40 & 12 & 28 & & & 10 & 30 & & & 10 & 30 & & \\
\hline \multirow[t]{2}{*}{$\gamma \mathrm{GT}-\mathrm{II}$} & + & 41 & 17 & 24 & 2.181 & 0.140 & 15 & 26 & 2.030 & 0.154 & 13 & 28 & 0.255 & 0.614 \\
\hline & - & 52 & 14 & 38 & & & 12 & 40 & & & 14 & 38 & & \\
\hline \multirow[t]{3}{*}{ Tumor size $(\mathrm{cm})$} & $\leq 5$ & 34 & 8 & 26 & 2.492 & 0.288 & 6 & 28 & 3.375 & 0.185 & 8 & 26 & 2.205 & 0.332 \\
\hline & $5-10$ & 34 & 14 & 20 & & & 12 & 22 & & & 13 & 21 & & \\
\hline & $\geq 10$ & 25 & 9 & 16 & & & 9 & 16 & & & 6 & 19 & & \\
\hline \multirow[t]{2}{*}{ Tumor number } & 1 & 58 & 18 & 40 & 0.367 & 0.545 & 14 & 44 & 1.792 & 0.181 & 15 & 43 & 0.752 & 0.386 \\
\hline & $\geq 2$ & 35 & 13 & 22 & & & 13 & 22 & & & 12 & 23 & & \\
\hline \multirow[t]{3}{*}{ Tumor grade } & $\mathrm{W}$ & 24 & 5 & 19 & 2.843 & 0.241 & 2 & 22 & 7.731 & 0.021 & 3 & 21 & 5.782 & 0.056 \\
\hline & M & 41 & 14 & 27 & & & 13 & 28 & & & 12 & 29 & & \\
\hline & $\mathrm{P}$ & 28 & 12 & 16 & & & 12 & 16 & & & 12 & 16 & & \\
\hline \multirow[t]{2}{*}{ TNM stage } & I -II & 51 & 15 & 36 & 0.782 & 0.377 & 12 & 39 & 1.660 & 0.198 & 12 & 39 & 1.660 & 0.198 \\
\hline & III-IV & 42 & 16 & 26 & & & 15 & 27 & & & 15 & 27 & & \\
\hline \multirow[t]{2}{*}{ Vein invasion } & Yes & 27 & 10 & 17 & 0.235 & 0.628 & 8 & 19 & 0.007 & 0.935 & 9 & 18 & 0.342 & 0.559 \\
\hline & No & 66 & 21 & 45 & & & 19 & 47 & & & 18 & 48 & & \\
\hline \multirow[t]{2}{*}{ Capsule formation } & Yes & 39 & 15 & 24 & 0.795 & 0.373 & 14 & 25 & 1.536 & 0.215 & 13 & 26 & 0.603 & 0.437 \\
\hline & No & 54 & 16 & 38 & & & 13 & 41 & & & 14 & 40 & & \\
\hline
\end{tabular}

Pearson's chi-square $(\chi 2)$ test or Fisher's exact test were used to analyze the correlation between SCCA variants and clinicopathological factors. Bold indicates statistical significance at $\mathrm{P}<0.05$.

Abbreviations: AFP, $\alpha$-fetoprotein; SCCA, Squamous cell carcinoma antigen; HBV, hepatitis B virus; HCC, hepatocellular carcinoma; HCV, hepatitis C virus; M, moderately differentiated; P, poorly differentiated; TNM, tumor node metastasis; W, well differentiated. 
Table S2 Clinical characteristics in relation to SCCA1 polymorphism

\begin{tabular}{|c|c|c|c|c|c|c|}
\hline Variable & & $\begin{array}{c}\text { Total } \\
\mathrm{n}\end{array}$ & SCCA1-wt & SCCA1-mut & $\chi^{2}$ & $\mathrm{P}$ \\
\hline \multirow[t]{2}{*}{ Sex } & Male & 24 & 9 & 15 & & 0.549 \\
\hline & Female & 3 & 2 & 1 & & \\
\hline \multirow[t]{2}{*}{ Age(years) } & $\leq 55$ & 14 & 7 & 7 & 1.033 & 0.310 \\
\hline & $>55$ & 13 & 4 & 9 & & \\
\hline \multirow[t]{2}{*}{$\mathrm{HBV}$} & + & 21 & 8 & 13 & & 0.662 \\
\hline & - & 6 & 3 & 3 & & \\
\hline \multirow[t]{2}{*}{$\mathrm{HCV}$} & + & 1 & 1 & 0 & & 0.407 \\
\hline & - & 26 & 10 & 16 & & \\
\hline \multirow[t]{2}{*}{ Liver cirrhosis } & Yes & 24 & 10 & 14 & & 1.000 \\
\hline & No & 3 & 1 & 2 & & \\
\hline \multirow[t]{2}{*}{ Child-Pugh score } & $\mathrm{A}$ & 23 & 9 & 14 & & 1.000 \\
\hline & $\mathrm{B}$ & 4 & 2 & 2 & & \\
\hline \multirow[t]{2}{*}{$\operatorname{AFP}(\mathrm{ng} / \mathrm{mL})$} & $\leq 400$ & 17 & 8 & 9 & 0.759 & 0.384 \\
\hline & $>400$ & 10 & 3 & 7 & & \\
\hline \multirow[t]{2}{*}{$\gamma$ GT-II } & + & 15 & 7 & 8 & 0.491 & 0.484 \\
\hline & - & 12 & 4 & 8 & & \\
\hline \multirow[t]{3}{*}{ Tumor size $(\mathrm{cm})$} & $\leq 5$ & 6 & 3 & 3 & 1.918 & 0.383 \\
\hline & $5-10$ & 12 & 6 & 6 & & \\
\hline & $\geq 10$ & 9 & 2 & 7 & & \\
\hline \multirow[t]{2}{*}{ Tumor number } & 1 & 14 & 5 & 9 & 0.304 & 0.581 \\
\hline & $\geq 2$ & 13 & 6 & 7 & & \\
\hline \multirow[t]{3}{*}{ Tumor grade } & $\mathrm{W}$ & 3 & 1 & 2 & 0.077 & 0.962 \\
\hline & M & 12 & 5 & 7 & & \\
\hline & $\mathrm{P}$ & 12 & 5 & 7 & & \\
\hline \multirow[t]{2}{*}{ TNM stage } & I -II & 12 & 7 & 5 & 2.769 & 0.096 \\
\hline & III-IV & 15 & 4 & 11 & & \\
\hline \multirow[t]{2}{*}{ Vein invasion } & Yes & 19 & 9 & 10 & & 0.405 \\
\hline & No & 8 & 2 & 6 & & \\
\hline \multirow[t]{2}{*}{ Capsule formation } & Yes & 13 & 8 & 5 & 4.492 & 0.034 \\
\hline & No & 14 & 3 & 11 & & \\
\hline
\end{tabular}

Pearson's chi-square $(\chi 2)$ test or Fisher's exact test were used to analyze the correlation between SCCA1 polymorphism and clinicopathological factors.

Bold indicates statistical significance at $\mathrm{P}<0.05$.

Abbreviations: AFP, $\alpha$-fetoprotein; SCCA, Squamous cell carcinoma antigen; HBV, hepatitis B virus; HCC, hepatocellular carcinoma; $\mathrm{HCV}$, hepatitis $\mathrm{C}$ virus; $\mathrm{M}$, moderately differentiated; $\mathrm{P}$, poorly differentiated; TNM, tumor node metastasis; $\mathrm{W}$, well differentiated. 
Table S3 Univariate and multivariate analyses of prognostic factors associated with overall survival in patients with HCC

\begin{tabular}{|c|c|c|c|c|c|}
\hline \multirow[t]{2}{*}{ Variable } & \multicolumn{2}{|c|}{ Univariate analysis } & \multicolumn{3}{|c|}{ Multivariate analysis } \\
\hline & $\chi^{2}$ & $\mathrm{P}^{*}$ & $\mathrm{HR}$ & $95 \%$ CI & $\mathrm{P}^{*}$ \\
\hline Age ( $\leq 55$ vs $>55$ years $)$ & 0.445 & 0.505 & - & - & NA \\
\hline Sex (male vs female) & 0.168 & 0.682 & - & - & NA \\
\hline $\operatorname{HBV}(+/-)$ & 0.005 & 0.942 & - & - & NA \\
\hline $\operatorname{HCV}(+/-)$ & 1.245 & 0.264 & - & - & NA \\
\hline Liver cirrhosis (Yes/No) & 0.560 & 0.454 & - & - & NA \\
\hline Child-Pugh score (A/B) & 4.001 & 0.045 & 4.416 & $1.784 \sim 10.935$ & 0.001 \\
\hline Tumor size $(\leq 5 / 5-10 />10 \mathrm{~cm})$ & 16.232 & 0.000 & 1.615 & $0.919 \sim 2.838$ & 0.096 \\
\hline Tumor number $(1 / \geq 2)$ & 8.381 & 0.004 & 1.036 & $0.483 \sim 2.222$ & 0.928 \\
\hline Tumor grade (W/M/P) & 4.237 & 0.040 & 1.170 & $0.740 \sim 1.849$ & 0.0503 \\
\hline TNM stage (I -II/III-IV) & 5.817 & 0.016 & 0.598 & $0.269 \sim 1.332$ & 0.208 \\
\hline AFP level $(\leq 400 />400 \mathrm{ng} / \mathrm{ml})$ & 6.140 & 0.013 & 1.671 & $0.785 \sim 3.553$ & 0.183 \\
\hline Vein invasion (Yes /No) & 22.913 & 0.000 & 1.916 & $0.938 \sim 3.912$ & 0.074 \\
\hline Capsule formation & 27.985 & 0.000 & 3.234 & $1.291 \sim 8.102$ & 0.012 \\
\hline SCCA1 mRNA (positive/negative) & 1.351 & 0.245 & - & - & NA \\
\hline SCCA2 mRNA (positive/negative) & 0.517 & 0.472 & - & - & NA \\
\hline
\end{tabular}

${ }^{*} \mathrm{P}<0.05$ was considered statistically significant (bold).

Abbreviations: 95\% CI, 95\% confidence interval; AFP, $\alpha$-fetoprotein; HBV, hepatitis B virus; HCC, hepatocellular carcinoma; HCV, hepatitis C virus; HR, hazard ratio; $\mathrm{M}$, moderately differentiated; NA, not available; P, poorly differentiated; SCCA, squamous cell carcinoma antigen; TNM, tumor node metastasis; $\mathrm{W}$, well differentiated. 